\title{
A new mutation in the human lipoprotein lipase gene causing familial hyperchylomicronaemia
}

\author{
R Anwar, J W L Puntis, A F Markham
}

\begin{abstract}
Lipoprotein lipase plays a major role in the regulation of lipid metabolism. The enzyme acts to hydrolyse triglycerides, providing free fatty acids for energy generation or storage, thus affecting the maturation of circulating lipoproteins. Biochemical and molecular analyses were performed on two siblings of consanguineous Pakistani origin, presenting with hyperchylomicronaemia, which revealed that the disorder resulted from lipoprotein lipase deficiency. Molecular analysis of the lipoprotein lipase gene has revealed a novel homozygous mutation, leucine to proline at amino acid residue 303 , within the amino terminal domain of the protein. (f Clin Pathol: Mol Pathol 1997;50:221-223)
\end{abstract}

Keywords: hyperchylomicronaemia; lipoprotein lipase; DNA mutation

Familial chylomicronaemia is a rare autosomal recessive genetic disorder occurring with a frequency of about 1 in 1000000 in most populations. The two major molecular defects responsible for this disorder are a deficiency of lipoprotein lipase (LPL) or its cofactor apolipoprotein C-II (apoC-II).

LPL is a key enzyme in the hydrolysis of triglycerides in plasma lipoproteins. LPL is secreted primarily by adipocytes and muscle cells into the circulation where it is bound, via glycosaminoglycan structures, to the luminal surface of capillary endothelial cells.' The active enzyme is a non-covalent homodimer of two glycoprotein chains, each of $\sim 55 \mathrm{kDa}$. In the presence of apoC-II, LPL hydrolyses triglycerides present in chylomicrons and very low density lipoproteins (VLDL) to liberate
mRNA is translated into a polypeptide of 448 amino acids. In this report, we present the biochemical and molecular genetic analysis of lipoprotein lipase deficiency in two siblings from Pakistan.

\section{Case reports}

Patient 1 was an 11 year old girl who was born at term following a normal pregnancy and delivery to first cousin Pakistani parents. At the age of 7 months she was referred to a paediatrician by her general practitioner because of pallor and recurrent vomiting. In the outpatient clinic she appeared to be unwell and was admitted for further investigation. According to her parents she had vomited after her feeds of formula milk ever since birth. Her developmental progress had been normal.

On admission she weighed $6.25 \mathrm{~kg}$, was febrile, and looked pale. Her liver was palpable $1 \mathrm{~cm}$ below the costal margin and there was $3 \mathrm{~cm}$ splenomegaly. Investigations revealed lipaemic serum, haemoglobin of $57 \mathrm{~g} / \mathrm{l}$, and normal creatinine, electrolytes, and liver function tests. Further studies on fasting blood yielded the following results: triglyceride $19.2 \mathrm{mmol} / 1$, cholesterol $5.9 \mathrm{mmol} / \mathrm{l}$, LPL $<1 \mathrm{mmol} / 1 / \mathrm{h}$ (normal range 5-9), apoC-II present, a large increase in the VLDL fraction, post-heparin sample showed increased mobility of VLDL, serum iron $<1 \mu \mathrm{mol} / 1$, haemoglobin electrophoresis normal.

A diagnosis of LPL deficiency was made and a low fat diet implemented. Iron deficiency was treated with an oral iron supplement. Subsequently, she has grown well, but despite good dietary compliance, she experiences recurrent bouts of abdominal pain and has required admission to hospital on 14 occasions, seven of these with pancreatitis.

A further child was born to the family two years later (patient 2). He was admitted to hospital following continued bleeding after circumcision and was noted to be anaemic and to have moderate hepatosplenomegaly. Investigations confirmed anaemia, with a haemoglobin of $82 \mathrm{~g} / 1$ and grossly lipaemic serum (triglyceride concentration $61.5 \mathrm{mmol} / \mathrm{l}$ ). The LPL deficiency in patient 2 was not measured as it was assumed he had the same condition as his sister. He has remained well on a low fat diet, except for one admission to hospital with \footnotetext{
free fatty acids. These can then be used as an energy source or re-esterified for storage. The clinical phenotype of LPL deficiency presents with abdominal pain, pancreatitis, hepatosplenomegaly, development of eruptive xanthomata or lipaemia retinalis, and failure to thrive. ${ }^{1}$

The LPL gene is located on chromosome $8 \mathrm{p} 22,{ }^{2}$ contains 10 exons, ${ }^{3}$ and transcribes two mRNA transcripts, of 3.75 and $3.35 \mathrm{~kb}$, as a result of alternative sites of $3^{\prime}$ terminal polyadenylation. The coding region of the

Correspondence to: Dr Anwar.

Accepted for publication 22 April 1997

Molecular Medicine Medicine, University Hospital, Leeds 7TF, UK
} 


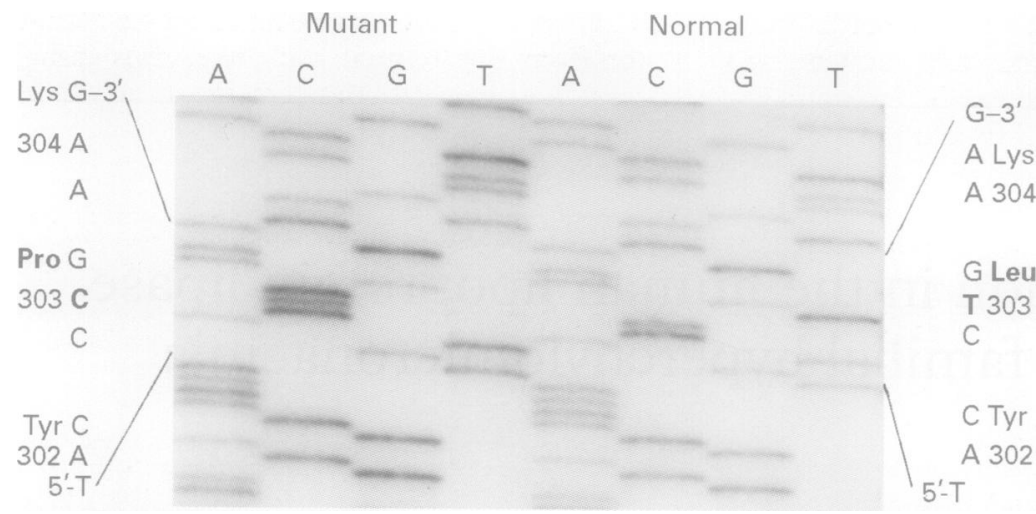

Figure 1 Exon 6 of the LPL gene, from patient 1 and a normal control, sequenced directly using the forward primer. The $T \rightarrow C$ mutation, Leu303Pro, identified is indicated. Patient 1 is homozygous for this sequence change.

abdominal pain in the absence of pancreatitis. Neither child has evidence of lipaemia retinalis or cutaneous xanthomata, but both have persistent mild hepatosplenomegaly. Both are growing normally and attend normal schools.

\section{Molecular analysis}

Exons 1-9 of the LPL gene (coding region) were amplified individually by the polymerase chain reaction (PCR) from both patients and an unrelated normal control as described previously. ${ }^{4}$ PCR products were desalted and purified from unincorporated nucleotides using Wizard DNA clean up columns (Promega, Birmingham, UK) following the manufacturer's protocol. The resulting DNA (25-50 fmols) was then used as the template for direct sequencing using the Sequenase sequencing kit (USB, Amersham, Bucks, UK) and $\gamma^{32} \mathrm{P}$ end labelled amplimers. Nucleotide sequence analysis showed that there was a

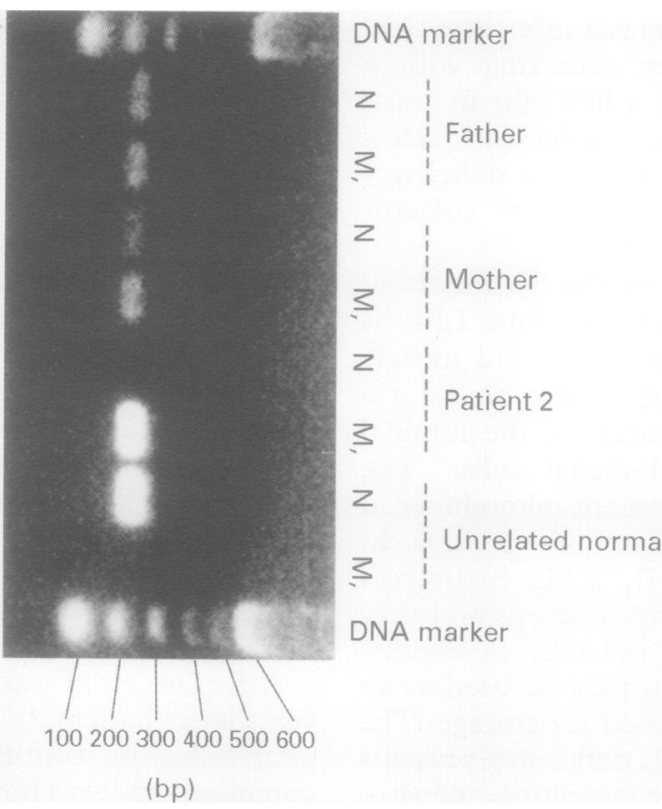

Figure 2 PCR products of 254 base pairs obtained using the normal and mutant reverse primers. Both the normal and mutant primers give PCR products from the parents, indicating they are heterozygous for this mutation. In patient 2, a PCR product is found only with the mutant primer, hence, this patient is homozygous for this mutation. The unrelated normal control gives a PCR product with the normal primer but not with the mutant primer, confirming it is normal homozygous. This latter pattern was obtained from all the 110 normal controls analysed. sequence change from $\mathrm{T} \rightarrow \mathrm{C}$ at nucleotide 1163 (numbered according to Wion et $a)^{5}$ of the coding region, within exon 6 (fig 1). This correlates to an amino acid change at codon 303, from leucine to proline (CTG $\rightarrow$ CCG). Both patients were found to be homozygous for 으 this mutation, probably owing to the parental 0 consanguinity. The mother and father were both heterozygous for this Leu303Pro mutation.

Exon 6 was analysed for the Leu303Pro mutation from 110 unrelated normal individuals by the amplification refractory mutation system-PCR technique. ${ }^{6}$ Exon 6 of the LPL gene was amplified from 110 normal unrelated individuals using the normal forward primer $\vec{\circ}$ (5'-dACCAGCTAGTGAAGTGCT-3'), and normal reverse primer, $N$ (5'dATCTGAGAACGAGTCTTCA-3'), or mutant reverse primer, $M$ (5'-dATCTGAGAA CGAGTCTTGG-3'). PCR conditions were: 35 cycles of $92^{\circ} \mathrm{C}$ for 30 seconds, $56^{\circ} \mathrm{C}$ for 30 seconds, and $72^{\circ} \mathrm{C}$ for 60 seconds. The PCR products obtained from the normal and 을 mutant alleles are displayed in fig 2. The $\rightarrow$ Leu303Pro mutation was not detected in any of the normal individuals examined, confirming that it is not a common population polymorphism and that, therefore, this muta- $\vec{b}$ tion is likely to be responsible for familial hyperchylomicronaemia in this family.

Analysis of the LPL gene from the unrelated normal control led to the identification of a further heterozygous mutation at codon 118 , GAG $\rightarrow$ GAA (data not presented). This sequence change is a silent mutation and hence does not affect the coding amino acid. Therefore, the frequency of this mutation was not examined within the normal population.

\section{Discussion}

The present study describes the biochemical and molecular genetic analysis of LPL deficiency in two siblings of consanguineous Pakistani origin. The biochemical analysis indicated LPL deficiency and this was confirmed by identification of a Leu303Pro homozygous mutation in the LPL gene. A number of mutations in the LPL gene have been described in recent years but the Leu303Pro mutation has not been observed in any other ethnic group studied so far. ${ }^{7}$

The lipase family of proteins have very complex three dimensional structures, consisting of multiple domains. Although the $x$ ray crystallography structure for LPL has not been determined, a molecular model of this protein has been predicted, based on the pancreatic lipase crystal structure, as LPL is highly homologous to this molecule. ${ }^{89} \mathrm{By}$ analogy with pancreatic lipase, LPL appears to be organised into two distinct domains, the amino terminal domain (residues 1-312) and a carboxyl terminal end (residues 313-448). The functional sites in the LPL protein include a site for interaction with lipid, as well as a catalytic site where triglyceride hydrolysis occurs, separate domains that mediate the binding of LPL to apoC-II and heparan sulphate, and sites involved in glycoprotein dimerisation. The Leu 303 residue in 
LPL is aligned to Leu 327 in pancreatic lipase and is conserved in human LPL and human and canine pancreatic lipase. This residue is within the amino terminal domain of LPL but does not seem to be involved directly in the catalytic site. Examination of the Leu 327 residue in human pancreatic lipase, using the graphics software RASMOL, shows that the conformation of this leucine is fully extended, and the side chain is packed into the molecule core. This conformation would not be possible with proline at this position, because proline is an imino acid, with a different torsion angle at its $\alpha$ carbon-nitrogen bond. Also, the proline nitrogen is unavailable to form hydrogen bonds with other residues within the protein. Hence, the Leu303Pro mutation would introduce some disturbance in the LPL structure. It is possible that proline at residue 303 could cause cis/trans disturbances such that the LPL protein would be unable to fold. It is also possible that the Leu303Pro mutant LPL does fold, but that the structure formed is thermally unstable or leads to an inactive enzyme. As the patients studied are actually deficient in LPL, it is probable that the Leu303Pro mutation disturbs the LPL folding pathway in such a way that, if the protein can fold, it is not a stable structure. Such a mutant LPL protein would be difficult to study functionally by expression in recombinant cells as similar structural instability problems would be encountered.

The GAG $\rightarrow$ GAA silent mutation at codon 118 does not affect the amino acid sequence of
LPL. However there may be an effect via codon usage from this sequence change, thus influencing the translational efficiency of LPL mRNA.

We thank our patients and their family for their cooperation and support. We are grateful to Professor SEV Phillips for assistance with the structural implications of this study. Work in our laboratories is supported by the Medical Research Council, Wellcome Trust, Northern and Yorkshire Regional Health Authority, West Riding Medical Research Trust, and Yorkshire Cancer Research Campaign.

1 Brunzell JD. Familial lipoprotein lipase deficiency and other causes of the chylomicronaemia syndrome. In: Scriver CR, Beaudet AL, Sly WS, Valle D, eds. The metabolic basis of inherited disease. New York: McGraw-Hill, 1995:1913-32.

2 Sparkes RS, Zollman S, Kilsak I, Kirchgessner TG, Komaromy MC, Mohandas T, et al. Human genes involved in lipolysis of plasma lipoproteins: mapping of loci for lipoprotein lipase to $8 \mathrm{p} 22$ and hepatic lipase to $15 \mathrm{q} 21$. Genomics $1987 ; 1: 138-44$.

3 Deeb SS, Peng R. Structure of the human lipoprotein lipase gene. Biochemistry 1989;28:4131-5.

4 Monsalve MV, Henderson H, Roederer G, Julien P, Deeb S, Kastelein JJP, et al. A missense mutation at codon 188 of the human lipoprotein lipase gene is a frequent cause of lipoprotein lipase deficiency in persons of different ancestries. $\mathcal{F}$ Clin Invest 1990;86:728-34.

5 Wion KL, Kirchgessner TG, Lusis AJ, Schotz MC, Lawn RM. Human lipoprotein lipase complementary DNA sequence. Science 1987;235:1638-41.

6 Newton CR, Heptinstall LE, Summers C, Super M, Schwarz M, Anwar R, et al. Amplification refractory mutation system for prenatal diagnosis and carrier assessment in cystic fibrosis. Lancet 1989;ii:1481-3.

7 Murthy V, Julien P, Gagne C. Molecular pathobiology of the human lipoprotein lipase gene. Pharmacol Therapeut 1996 70:101-35.

8 Santamarina-Fojo S, Brewer HB Jr. Lipoprotein lipase: structure, function and mechanism of action. Int $f$ Clin Lab Res 1994;24:143-7.

9 van Tilbeurgh $H$, Roussel A, Lalouel J-M, Cambillau C. Molecular model based on the pancreatic lipase X-ray structure: consequences for heparin binding and catalysis. $\mathcal{F}$ Biol Chem 1994;269:4626-33. 